\title{
First Record of the Blue Crawfish, Cambarus monongalensis Ortmann, 1905 (Decapoda: Cambaridae), from Ohio, USA
}

MAEL G. GLON ${ }^{1}$, Museum of Biological Diversity, The Ohio State University, Columbus, OH, USA; LAURA S. HUGHES, Pataskala, OH, USA; HEATHER E. GLON, Museum of Biological Diversity, The Ohio State University, Columbus, OH, USA; KELLY M. CAPUZZI, Southeast District Office, Ohio Environmental Protection Agency, Logan, OH, USA; ZACHARY J. LOUGHMAN, Department of Biological Sciences, West Liberty University, West Liberty, WV, USA; and ROGER F. THOMA, Midwest Biodiversity Institute, Hilliard, $\mathrm{OH}$, USA.

ABSTRACT. This paper documents the first record of the blue crawfish, Cambarus monongalensis Ortmann, 1905, in the state of Ohio, United States. The blue crawfish is a small- to medium-sized primary burrowing crayfish common in western Pennsylvania and West Virginia. Because of the prevalence of this species on the east side of the Ohio River, numerous researchers have sought the blue crawfish in Ohio-to no avail. On 16 May 2020, turkey hunters in Monroe County, Ohio, located a blue-colored crayfish and sent photos to one of the authors of this study. On 19 May 2020, the authors sampled in the vicinity of where the photo was taken and located 4 sites that yielded a total of 5 blue crawfish specimens, confirming the existence of this species in Ohio. Further research is needed on the blue crawfish to determine its range and abundance in Ohio, and to explore factors relating to its biogeography.

OHIO J SCI 120(2):57-60

\section{INTRODUCTION}

Editor's note: The occasional use of "crawfish" rather than "crayfish" in this paper is intentional and is based on the common name "blue crawfish" chosen by Ortmann (1905) when he described this species.

This paper documents the first record of the blue crawfish, Cambarus monongalensis Ortmann, 1905, in Ohio, United States. The blue crawfish is a smallto medium-sized primary burrowing crayfish first described from Frick Park in Pittsburgh, Allegheny County, Pennsylvania, United States, by Ortmann (1905). This species inhabits shallow burrows which it excavates in montane seepage wetlands, springs, headwater stream riparian zones, and roadside ditches in mixed mesophytic forests (Ortmann 1906; Jezerinac et al. 1995). Populations of this species are generally disjunct and limited to 10 to $20 \mathrm{~m}^{2}(108$ to $215 \mathrm{ft}^{2}$ ), although riparian zone populations can be larger and occupy a greater area (Jezerinac et al. 1995; Loughman et al. 2017). By these measures, this crayfish is inconspicuous; however, the entire body of this crayfish is a striking blue color except for the tips of the chelae which are bright red-orange. Likely because of its color, the blue crawfish readily attracts attention outside the safety of its burrow.

${ }^{1}$ Address correspondence to Mael G. Glon, Museum of Biological Diversity, The Ohio State University, 1315 Kinnear Road, Columbus, OH 43212-1157, USA.

Email: glon.1@osu.edu
Since its original description in 1905, the blue crawfish has been recorded in the upper Ohio River Basin in parts of Pennsylvania and West Virginiabut never Ohio (Fig. 1). The little brown mudbug, Lacunicambarus thomai (Jezerinac, 1993), is the only other primary burrowing species that occurs in this region of Pennsylvania and West Virginia, but its range also extends across the Ohio River into Ohio where it is common in the eastern half of the state. Numerous researchers have, therefore, suspected that the blue crawfish should also occur in Ohio. Most notably, co-author R. Thoma and his late mentor Professor Raymond F. Jezerinac searched for the blue crawfish in eastern Ohio for years, starting in 1975 and continuing intermittently throughout the 1970s and 1980s. Searches have been undertaken in recent years by co-authors R. Thoma, M. Glon, Z. Loughman, and L. Hughes following reports from landowners of blue crayfish which, in all cases, turned out to be blue-tinted specimens of known Ohio crayfish such as the rock crawfish, $C$. carinirostris Hay, 1914 (Faxon 1914). These searches resulted in a total of 178 sites sampled in Jefferson, Monroe, and Belmont Counties over a 45-year period. None of these sampling attempts have succeeded until now.

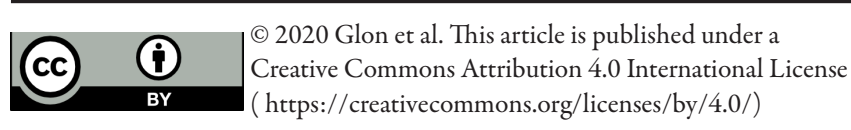




\section{METHODS AND MATERIALS}

On 16 May 2020, co-author L. Hughes received photographs of a blue crayfish from friends who were turkey hunting in Monroe County, Ohio. She immediately contacted co-authors $\mathrm{M}$. Glon and R. Thoma to share these photographs. On 19 May 2020, all the authors sampled in the vicinity of where the photos were taken. This site is a northwest-facing steep hillside ranging from 230 to $350 \mathrm{~m}$ (755 to $1,148 \mathrm{ft})$ in elevation. At an elevation of $330 \mathrm{~m}(1,083$ $\mathrm{ft}) \mathrm{a}$ vein of shale and mudstone is present where several fractures allow vadose water to emerge at the surface, leading to a multitude of seepage wetlands and springs. Woody vegetation associated with these seepage wetlands and springs includes, but is not limited to, species of maples (particularly sugar maple (Acersaccharum)), elms (Ulmus americana and Ulmus rubra), and black cherry (Prunus serotina). Understory woody vegetation consists of northern spicebush (Lindera benzoin) and multiflora rose (Rosa multiflora), the latter having invaded and become dominant in the area. Several plants, characteristic of seepage wetlands, are also present at this site including mosses, Hepatica sp., sensitive fern (Onoclea sensibilis), Christmas fern (Polystichum acrostichoides), and Equisetum sp. On the same day, co-author R. Thoma also sampled a roadside ditch on an oak-dominated hillside approximately 2.4 $\mathrm{km}$ (1.49 mi) away.

Sampling at both sites first consisted of locating crayfish burrows, most of which were 2.5 to $4 \mathrm{~cm}$ (1 to 1.6 in) diameter holes, although a few were topped with rudimentary chimneys (Fig. 2) or plugged. Burrows were excavated by hand, or with the help of a small gardening pickaxe or shovel, to collect the specimens. Locality and habitat data were recorded from each site. Specimens $(n=4)$ were later preserved in $70 \%$ ethanol and deposited in The Ohio State University Museum of Biological Diversity Crustacea Collection (Catalogue Numbers: OSUMC 10884 and 10885).

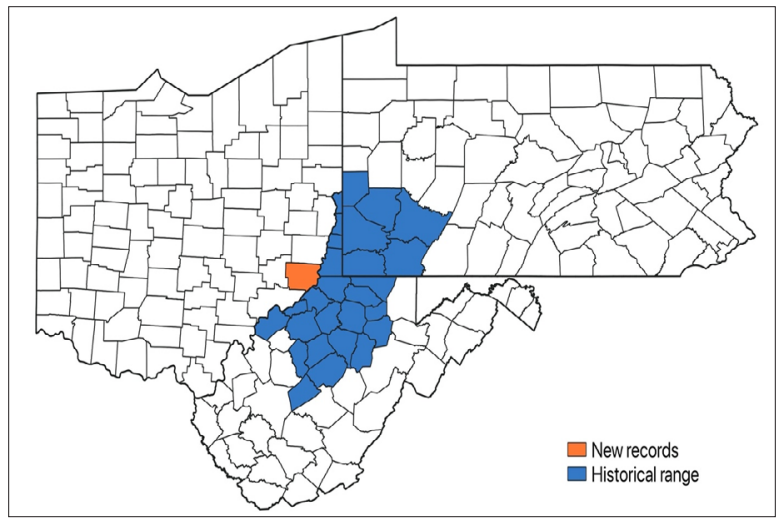

FIGURE 1. Map of Ohio, Pennsylvania, and West Virginia showing the county-level range of blue crawfish, Cambarus monongalensis. Blue-colored counties represent the historical range of the species, the orange-colored county depicts new records in Ohio.

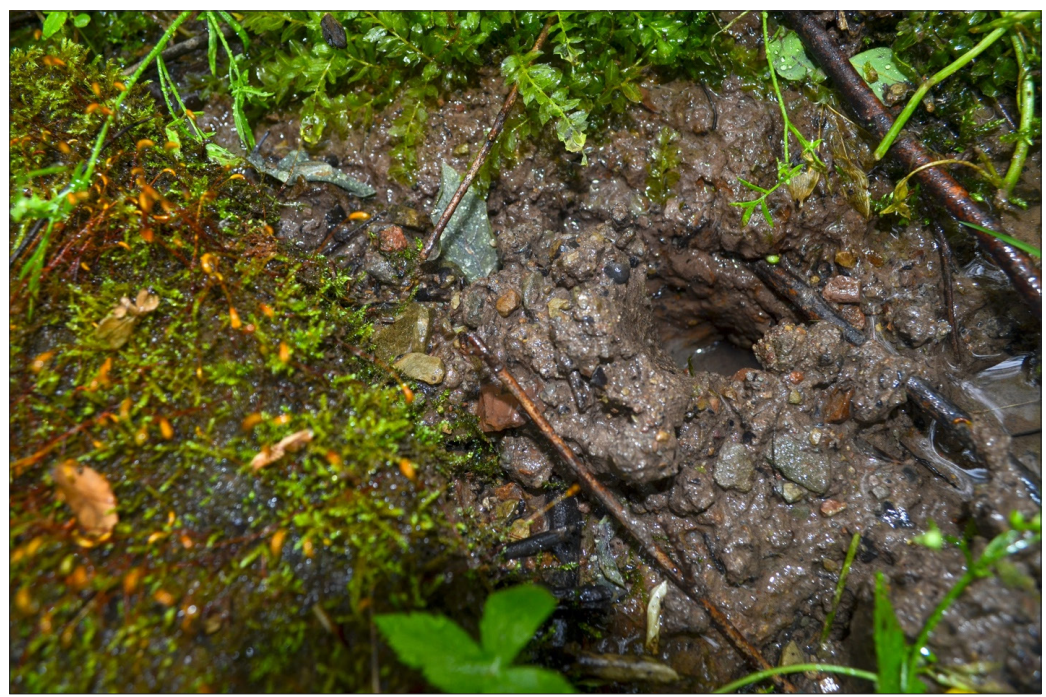

FIGURE 2. Blue crawfish, Cambarus monongalensis, burrow topped by rudimentary chimney. Photo credit: H. Glon. 


\section{RESULTS}

Excavation of numerous crayfish burrows - in a ditch and a spring modified for water supply near the base of the hill —at the sampling site yielded only Appalachian brook crayfish, C. bartonii cavatus Hay, 1902. Cambarus b. cavatus and $C$. monongalensis are only rarely found cohabitating in West Virginia (Jezerinac et al. 1995; Z. Loughman personal observation). Searchers then worked up the hillside looking for wet areas, such as seepage wetlands and springs, capable of harboring colonies of burrowing crayfish. Three seepage wetlands with crayfish burrows were located at the toe of a bench running along the hillside site (Fig. 3). These seepage wetlands were approximately $15 \mathrm{~m}$ (49 ft) apart along an east to west transect, but lacked any apparent above-ground connection to each other or any downhill waterbodies.

A blue crawfish specimen (Fig. 4) was collected at each of the 3 seepage wetlands. A single blue crawfish was also collected from a burrow at the roadside ditch site. In total, 1 form II male and 3 females were collected ( 1 additional female specimen from the hillside site was released after identification). Both sites likely harbored more blue crawfish, as evidenced by additional active burrows, but collections were limited to minimize impact to these populations. Crayfish were identified primarily based on their characteristic color, but their identity was confirmed by examining other distinguishing characteristics including the shape of the rostrum and chela, and tuberculation of the chela.

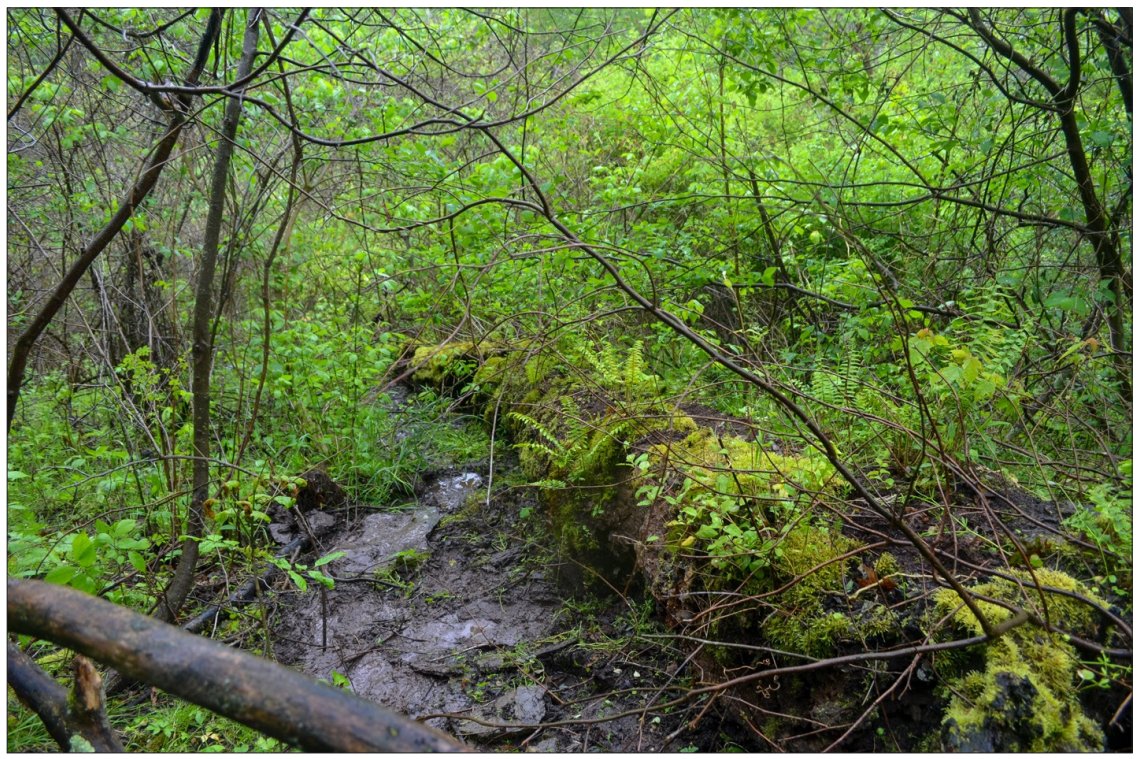

FIGURE 3. Seepage wetland with crayfish burrows at hillside sampling site. Photo credit: H. Glon.

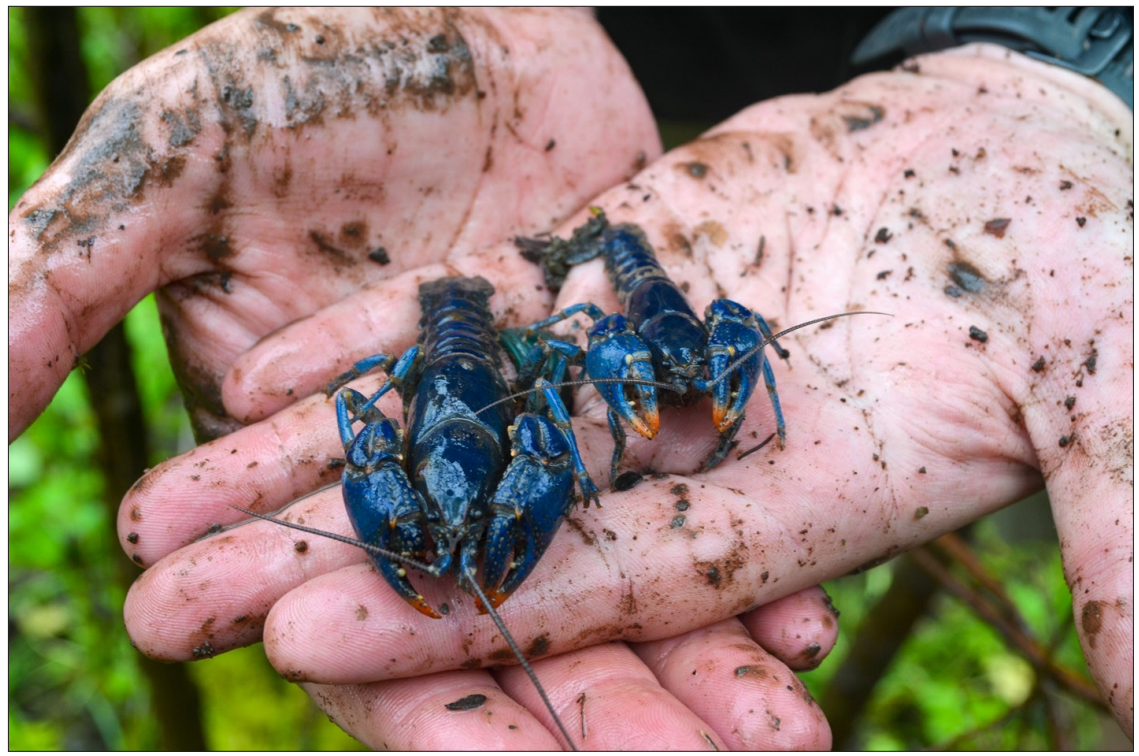

FIGURE 4. Female (left) and form II male (right) blue crawfish, Cambarus monongalensis, collected at hillside sites. Photo credit: H. Glon. 


\section{DISCUSSION}

The discovery of this species in Ohio represents a new state record that required decades to find, but of greater importance are the biogeographic implications of this species' presence west of the Ohio River. It is unknown at this time how widespread the blue crawfish is in Ohio, but past surveys suggest that it is very narrowly distributed. This species is, contrarily, relatively common east of the Ohio River, in parts of West Virginia and Pennsylvania (Fig. 1) (Jezerinac et al. 1995; Loughman et al. 2017). Why the blue crawfish is so narrowly distributed west of the Ohio River - and why it occurs in this specific area-is yet undetermined, but warrants future determination.

Further research is needed on the blue crawfish in Ohio. Its range and abundance must be determined to inform a conservation assessment. In addition, population genetic methods should be utilized to delve deeper into the biogeography of this species to determine (1) approximately how long the Ohio population has been isolated from those in Pennsylvania and West Virginia and (2) to explain the mechanisms that led to it becoming isolated.

\section{ACKNOWLEDGEMENTS}

The authors are grateful to the landowners for allowing us to sample on their property and to the turkey hunters for discovering the first blue crawfish specimen and notifying us of their remarkable find (all names have been removed to preserve privacy).

\section{LITERATURE CITED}

Faxon W. 1914. Notes on the crayfishes in the United States National Museum and the Museum of Comparative Zoology with descriptions of new species and subspecies to which is appended a catalogue of the known species and subspecies. Mem Mus Comp Zool Harvard Coll. 40(8):351-427. 13 plates. https://doi.org/10.5962/bhl.title.49092

Hay WP. 1902. Observations on the crustacean fauna of Nickajack Cave, Tennessee, and vicinity. Proc US Natl Mus. 25(1292):417-439. https://doi.org/10.5479/si.00963801.25-1292.417

Jezerinac RF. 1993. A new subgenus and species of crayfish (Decapoda: Cambaridae) of the genus Cambarus, with an amended description of the subgenus Lacunicambarus. Proc Biol Soc Wash. 106(3):532-544.

https://www.biodiversitylibrary.org/page/34574364

Jezerinac RF, Stocker GW, Tarter DC. 1995. The crayfishes (Decapoda: Cambaridae) of West Virginia. Columbus (OH): Ohio Biological Survey. 193 p. Bulletin (new series) vol. 10, no. 1. ISBN13: 9780867271133.

http://www.ohiobiologicalsurvey.org/books_posters/

Loughman ZJ, Lieb DA, Scott RK, Dillard ZW, Sadecky NM. 2017. Historical and current distribution of Appalachian primary burrowing crayfishes (Decapoda: Astacoidea: Cambaridae) in western Pennsylvania: a century of change or stasis? J Crustacean Biol. 37(5):535-543.

https://doi.org/10.1093/jcbiol/rux050

Ortmann AE. 1905. The crawfishes of western Pennsylvania. Ann Carnegie Mus. 3(2):387-406. https://doi.org/10.5962/bhl.title.16015

Ortmann AE. 1906. The crawfishes of the state of Pennsylvania. Mem Carnegie Mus. 2(10):343-523. 7 plates. https://doi.org/10.5962/bhl.title.10407 